\title{
Imaging features of breast cancer molecular subtypes: An Updated Review of the Literature
}

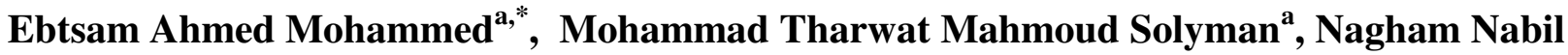 Omar $^{\mathrm{b}}$, Nahla Mohamed Ali Hasan ${ }^{\mathrm{a}}$}

${ }^{a}$ Department of Radio-Diagnosis, Faculty of Medicine, Sohag University, Sohag, Egypt.

${ }^{b}$ Department of Radio-Diagnosis, Faculty of Medicine, Assiut University, Assiut, Egypt.

\begin{abstract}
Background: Breast carcinoma is classified in keeping with its morphologic features. As regards the WHO classification, the histopathological kinds of the breast carcinoma; ductal carcinomas, lobular carcinomas, and uncommon kinds, these are associated with particular imaging features, primarily based on every kind. Additionally, predictive biologic markers along with estrogen, progesterone receptors, HER2 receptor status, and Ki-67 may be suitable to subclassify breast carcinoma into the intrinsic subtypes primarily based totally on gene expression profiling into: Luminal A, Luminal B, HER2+, and Triple Negative. Correlation among the imaging and the molecular subtypes has discovered an enormously circumscribed lesions with posterior acoustic enhancement without calcification inside the triple negative breast cancer subtype, microcalcifications are seen with the HER2+ subtype, but speculated lesions of irregular margin and posterior acoustic shadow with the luminal A and B subtypes, MRI is a longtime supplemental method to mammography and ultrasonography for the assessment of breast lesions. Diffusion-weighted MR imaging (DWI) has lately been incorporated into the breast MRI, moreover dynamic contrast enhanced MRI (DCE-MRI).

Conclusion: Understanding medical collaboration of molecular subtypes and imaging features can assist the radiologist to help the clinician to adjust treatment consistent with the patient condition and tumor characteristics.
\end{abstract}

Keywords: Breast Carcinoma, WHO, Molecular Subtypes, DCE-MRI, DWI.

\section{Introduction}

Breast cancers can be a group of diseases described by its pathological (e.g., ductal, lobular, mucinous) and molecular subtypes (e.g., estrogen receptor (ER), progesterone receptor (PR), HER2 amplification, and currently transcriptome primarily based classifications like luminal and basal cancers) (Jenkins et al., 2021). Initially, the WHO described breast carcinoma via means of its morphological characters into invasive ductal carcinoma (IDC), invasive lobular carcinoma (ILC), medullary carcinoma, mucinous carcinoma, and also tubular carcinoma (Boisserie et al., 2013).Molecular subtyping is useful for the prognosis and special treatment of breast cancer. However, the dedication of subtypes via genetic analysis is invasive and expensive, requiring most cancers specialized centers and technical expertise. Immunohistochemical surrogate biomarkers of estrogen receptor (ER), progesterone receptor $(\mathrm{PR})$, and HER2 reputation are used to outline molecular subtypes. Therefore, needs multiplied for opportunity techniques of classifying breast cancers into its molecular subtypes. MRI has performed an evolving role within the diagnosis and 
management of breast carcinoma (Fan et al., 2017).Regarding imaging, DCE-MRI and DWI at the moment are broadly identified and globally used modalities in MP-MRI to diagnose and stage carcinoma, to evaluate post chemotherapy response, and to distinguish among scar tissue and recurrent tumor(Allarakha et al., 2019).

Initially, the WHO described breast carcinoma via means of its morphological and immunohistochemical characters. The 4 th version of WHO classification of breast tumors is a replace to the 3rd version. Changes within the 4th version consist of adjustments within the terminology that constitute to our current knowledge of these lesions (Sinn et al., 2013).Major adjustments are proven within the new WHO classification of tumors, fifth version, that's a replace of the 4th version breast tumors posted in 2012, the descriptions of breast tumors follows the preceding volumes, now prepared in series from benign epithelial proliferations and precursors, benign neoplasms, to in situ and invasive carcinomas, observed via means of mesenchymal and hemato-lymphoid neoplasms, and genetic tumor syndromes (Tan et al., 2020).

\section{Specific subtypes of Invasive Breast Carcinoma:}

The common specific subtypes include in situ carcinomas, invasive breast carcinomas of no special type (IDC-NST), lobular, cribriform, tubular, mucinous, papillary, metaplastic carcinomas and carcinomas with medullary pattern and lesions with apocrine differentiation. These particular tumor kinds are described via means of their morphology, however are connected to precise clinical, epidemiological, and molecular features (Cserni et al., 2020).

\section{Invasive ductal carcinoma (IDC):}

IDC constitutes about $80 \%$ of the invasive cancers. It has apparently a star-shaped outlines. The histopathological grade takes into attention the differentiation, nuclear atypia and mitosis, to determine the different grades of malignancy (fig. 1b), within the imaging it appear as: irregular or stellar mass (fig. 1a), architectural distortion, microcalcification, and rarely a round mass (Boisserie et al., 2013).

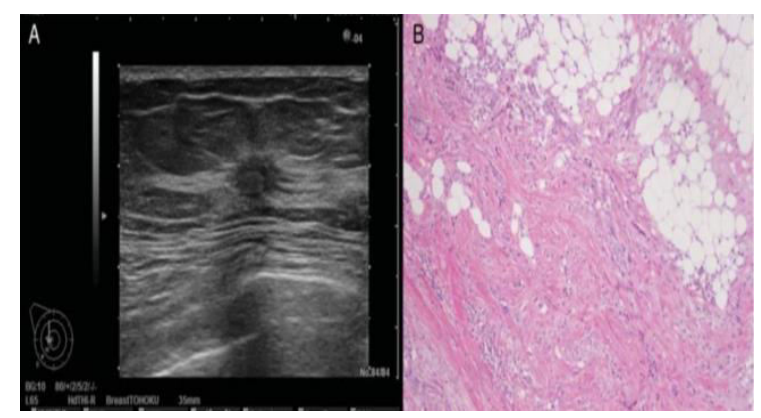

Fig.1. Representative illustrations of 'halo'. (a) 'Halo' of the US finding. (b) The histopathologic feature representing infiltration of carcinoma cells into the surrounding tissues (Tamaki et al., 2010).

\section{Invasive lobular carcinoma (ILC):}

ILC constitutes about $10 \%$ of the invasive cancers. The lesion is more palpable than visible. Tumor infiltration usually adjusts to the pre-existent construction of the breast tissue. The loss of expression of $\mathrm{CDH} 1$ gene which provides instructions for making a protein called epithelial cadherin or Ecadherin, an intercellular protein that helps neighboring cells stick to one another (cell adhesion) to form organized tissues, defines ILCs whose cells are no longer adherent. The cells are scattered or arranged in rows, surround the ducts or infiltrate adipose tissue without stromal reaction (Fig. 2a, 2b). This is partly responsible for the difficulties in detecting it in mammography, where it appears as a focal asymmetry, or an isolated architectural distortion, microcalcifications 
are rare (Fig. 2c), (Boisserie et al., 2013).MRI is the simplest examination to detect and measure the size of ILC (Sardanelli et al., 2010).

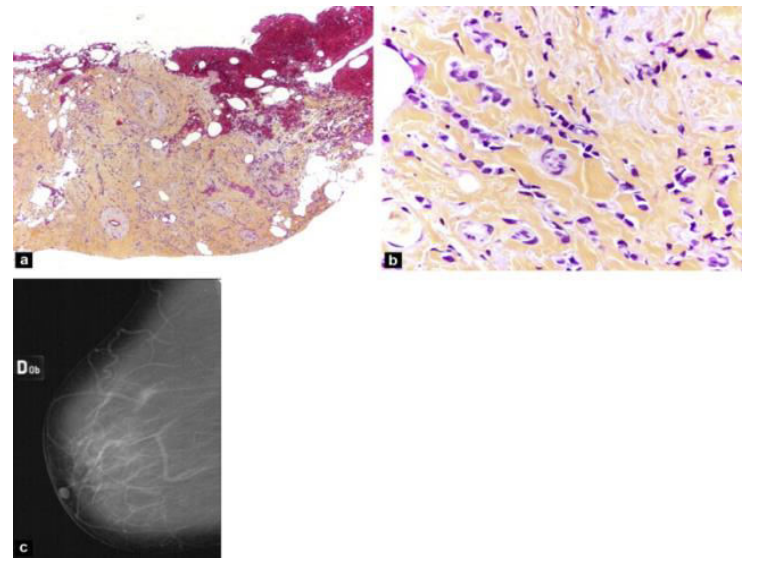

Fig.2. Invasive lobular carcinoma.a: invasion of the fatty breast tissue by scattered cells without stromal reaction; $b$ : Arrangement of cells in rows; c: mammography, right MLO image: focal hyperdense area at the union of the upper outer quadrant(Boisserie et al., 2013).

\section{Correlation between imaging features and tumor grades:}

Both grade I and grade II tumors exhibit stromal reaction responsible for the spicules within the lesion (fig. 3a). Grade III tumors are aggressive, they do not develop stromal reaction and have rounded shape, these tumors respond well to chemotherapy. They appear as extremely dense masses with circumscribed or microlobulated outline, and posterior enhancement (fig. 3b) these tumors are associated with negativity of the hormone receptors(Shin et al., 2011).

\section{Immunohistochemistry}

Determinations of estrogen receptor (ER), progesterone receptor (PR), human epidermal protein receptor 2 (HER2), and Ki67 status immunohistochemically, can define these subtypes. The prognosis differs between these subtypes. Luminal A and B tumors have the most favorable prognosis, while HER2+ and triple negative tumors have the worst prognosis.
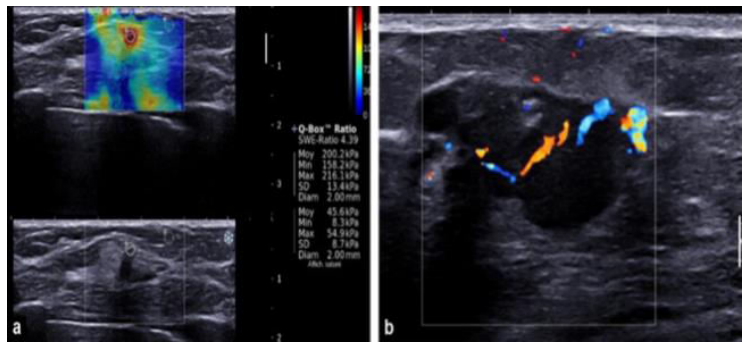

Fig.3. Ultrasonography in relation to tumor grades.a: IDC grade I: mass with a central hypoechoic area surrounded by denseechogenic halo in elastography. b: IDC grade III: hypoechoic, oval shaped vascularized mass with circumscribed outline, and posterior enhancement (Boisserie et al., 2013).

With the techniques of DNA microarray expression profiling, an organized classification method is used to identify the four distinct molecular subtypes: Luminal A (Estrogen receptor and/or progesterone receptor positive, HER2 negative); Luminal B (Estrogen receptor and/or progesterone receptor positive, HER2 positive or Ki67 > 14\%); HER2+ (HER2 amplified), Estrogen receptor and/or progesterone receptive negative; and Triple negative (TNBC) (ER, PR, and HER2 are negative) (Sohn et al., 2016).

\section{New molecular classification}

The essential molecular categories of invasive carcinomas described on the concept of different genes expressionwhich is compatible with the type of tumor (Prat et al., 2011). 
Table 1. Intrinsic subtypes of breast cancer with their surrogate definitions, prognosis and treatment (Szymiczek et al., 2021).

\begin{tabular}{|c|c|c|c|c|c|c|}
\hline \multirow[b]{2}{*}{$\begin{array}{l}\text { Intrinsic } \\
\text { subtype }\end{array}$} & \multicolumn{4}{|c|}{ Surrogate Immunohistochemicaldefinition } & \multirow[b]{2}{*}{ Prognosis } & \multirow[b]{2}{*}{ Treatment } \\
\hline & ER & $\overline{\mathbf{P R}}$ & HER2 & Ki-67 & & \\
\hline Luminal A & $\begin{array}{c}\text { positiv } \\
\mathrm{e}\end{array}$ & positive & negative & $\begin{array}{c}\text { low }<14 \% \\
\text { or recently } \\
<20 \%\end{array}$ & good & $\begin{array}{l}\text { hormonal } \\
\text { treatment } \\
\text { alone or with } \\
\text { chemotherap } \\
\text { y }\end{array}$ \\
\hline Luminal B & $\begin{array}{c}\text { positiv } \\
\mathrm{e}\end{array}$ & $\begin{array}{l}\text { positive } \\
\text { or } \\
\text { negativ } \\
\mathrm{e}\end{array}$ & $\begin{array}{c}\text { positive or } \\
\text { negative }\end{array}$ & $\begin{aligned} & \text { high } \\
\geq & 14 \% \text { or } \\
\text { recently } & \geq 20 \%\end{aligned}$ & moderate & $\begin{array}{l}\text { hormonal } \\
\text { treatmentand } \\
\text { chemotherap } \\
\mathrm{y}+/- \\
\text { trastuzumab }\end{array}$ \\
\hline HER2+ & $\begin{array}{c}\text { negati } \\
\text { ve }\end{array}$ & $\begin{array}{c}\text { negativ } \\
\mathrm{e}\end{array}$ & $\begin{array}{c}\text { overexpress } \\
\text { ed or } \\
\text { amplified }\end{array}$ & $\begin{array}{l}\text { low or } \\
\text { high }\end{array}$ & $\begin{array}{c}\text { bad, but } \\
\text { improved by } \\
\text { treatment }\end{array}$ & $\begin{array}{c}\text { Chemotherap } \\
\text { y with } \\
\text { trastuzumab. }\end{array}$ \\
\hline $\begin{array}{c}\text { Triple } \\
\text { Negative }\end{array}$ & $\begin{array}{c}\text { negati } \\
\text { ve }\end{array}$ & $\begin{array}{c}\text { negativ } \\
\mathrm{e}\end{array}$ & negative & $\begin{array}{l}\text { low or } \\
\text { high }\end{array}$ & bad & $\begin{array}{c}\text { chemotherap } \\
\mathrm{y}\end{array}$ \\
\hline
\end{tabular}

\section{Luminal B subtype}

\section{Luminal A subtype}

Expresses a cellular protein located in the lumen of the channels, therefore called "luminal". It represents about $37.8 \%$ of all invasive breast cancers. Its grade is I or II; most are well differentiated non-specific type (NST) carcinomas, lobular carcinomas, mucinous, tubular, cribriform, and neuroendocrine carcinomas. Immunohistochemically: ER +ve, PR +ve ( $\geq 20 \%$ ), HER2 -veand a low Ki67. 14\% was the cut-off point of $\mathrm{Ki} 67$ to discriminate luminal A from luminal B subtypes, but more recently this value has modified to 20\% (Fragomeni et al., 2018).
Represents about $36.8 \%$ of all invasive breast cancers. Its histopathological grade is II or III; mainly invasive ductal carcinomas (NST) and also some invasive micropapillary carcinomas. Immunohistochemically: ER +ve, low PR $(<20 \%)$, HER2 -ve, and high level of Ki67 ( $>14 \%$ and recently $>20 \%$ ). It appears that luminal $\mathrm{A}$ and luminal $\mathrm{B}$ tumors have distinct genetic structures which determine oncogenic proliferation(Fragomeni et al., 2018).

\section{HER2+ subtype}

HER2+ overexpressing tumors are found in $12.5 \%$ of invasive breast cancers and present a worse prognosis but respond well to therapies targeting HER2 receptors. There are inherent heterogeneous subtypes within 
HER2+ tumors, indicating the potential to predict the grade of response of the patient to trastuzumab. In HER2+ breast cancer, hormonal receptor positive tumors were correlated with increased disease free survival and overall survival compared to hormonal receptor negative tumors. During the first 5 years of follow-up from National Comprehensive Cancer Network centers, there're more reported recurrence rates in the hormonal receptor negative tumor group compared to the hormonal receptor positive group(Cho et al., 2016).

Its histopathological grade is II or III; NST invasive carcinoma, pleomorphic lobular, and apocrine carcinomas. Thus, immunohistochemically, HER2+ tumors are divided into two subtypes: the HER2 enriched subtype (ER and / or PR -ve / HER 2 +ve) and the luminal HER2 subtype (ER and / or PR +ve, HER2 +ve); and divided into two types according to the PR expression: ER +ve, PR+ve, HER2+veand ER +ve, PR-ve, HER2+ve(Prat et al., 2011).

\section{Triple-negative subtype}

TNBC represent $12.9 \%$ of all invasive cancers, TNBC is defined as there is no expression of ER, PR and HER2. Despite its simple definition, it is genetically, morphologically and clinically heterogeneous category of carcinoma, mainly medullary carcinoma, secretory carcinoma, carcinoma with apocrine features, and adenoid cystic carcinoma (Sinn et al., 2013).

TNBC has the worst prognosis. The majority $(86 \%)$ of triple negative breast cancers (TNBC), those showing ER, PR and HER2 negative stand for the basal-like subtype, the terms TNBC and basal-like have been used exchangeable to express the tumor subtype. However, all intrinsic subtypes exist within the type of TNBC (Prat et al., 2015).

Table 2. Molecular subtypes of breast cancer as regardimmunohistochemical studies and their main clinicopathological characteristics (Johnson et al., 2021).

\begin{tabular}{|c|c|c|c|c|c|c|}
\hline & \multicolumn{2}{|c|}{ Luminals } & \multirow{2}{*}{\multicolumn{2}{|c|}{$\begin{array}{l}\text { HER2 } \\
12.5 \% \\
\end{array}$}} & \multirow{2}{*}{\multicolumn{2}{|c|}{$\begin{array}{c}\text { Triple-negative } \\
12.9 \%\end{array}$}} \\
\hline Frequency & $37.8 \%$ & $36.8 \%$ & & & & \\
\hline $\begin{array}{l}\text { Molecular } \\
\text { subtype }\end{array}$ & $\begin{array}{c}\text { Lumina } \\
\text { IA }\end{array}$ & Luminal B & Luminal & $\begin{array}{c}\text { Enriche } \\
\text { d }\end{array}$ & $\begin{array}{c}\text { Non } \\
\text { basal- } \\
\text { like }\end{array}$ & $\begin{array}{l}\text { Basal- } \\
\text { like }\end{array}$ \\
\hline $\begin{array}{l}\text { Estrogen } \\
\text { receptor }\end{array}$ & positive & positive & positive & $\overline{\text { negative }}$ & $\begin{array}{c}\text { negativ } \\
\mathrm{e}\end{array}$ & $\begin{array}{c}\text { negativ } \\
\mathrm{e}\end{array}$ \\
\hline $\begin{array}{l}\text { Progesterone } \\
\text { receptor }\end{array}$ & $\begin{array}{l}\text { positive } \\
(>20 \%)\end{array}$ & $\begin{array}{c}\text { positive/negati } \\
\text { ve }\end{array}$ & $\begin{array}{c}\text { positive/negati } \\
\text { ve }\end{array}$ & negative & $\begin{array}{c}\text { negativ } \\
\mathrm{e}\end{array}$ & $\begin{array}{c}\text { negativ } \\
\mathrm{e}\end{array}$ \\
\hline HER2 & negative & negative & positive & positive & $\begin{array}{c}\text { negativ } \\
\mathrm{e}\end{array}$ & $\begin{array}{c}\text { negativ } \\
\mathrm{e}\end{array}$ \\
\hline $\begin{array}{l}\text { Histopathologic } \\
\text { al grade }\end{array}$ & I\&II & II\&III & III & III & III & III \\
\hline Ki-67 & $<14 \%$ & $14-30 \%$ & $>14 \%$ & $\overline{\text { High }}$ & High & High \\
\hline
\end{tabular}




\begin{tabular}{|l|l|l|l|l|l|l|}
\hline Mutations & & BRCA2 & & $\begin{array}{l}\text { In p53 } \\
(40- \\
80 \%)\end{array}$ & $\begin{array}{l}\text { In } \\
\text { p53(40 } \\
-100 \%) \\
85 \% \text { of } \\
\text { BRCA } \\
1\end{array}$ \\
\hline $\begin{array}{l}\text { Histopathologic } \\
\text { al types }\end{array}$ & $\begin{array}{l}\text { Tubular } \\
\text { CA, } \\
\text { IDC, } \\
\text { Low } \\
\text { grade } \\
\text { UC }\end{array}$ & & & & & \\
& & & & $\begin{array}{l}\text { Poorly } \\
\text { differentiated } \\
\text { IDC, metaplastic } \\
\text { and some with a } \\
\text { better prognosis: } \\
\text { Medullary } \\
\text { CA, } \\
\text { Adenoid-cystic, } \\
\text { Apocrine, } \\
\text { Fibromatosis- } \\
\text { like.... }\end{array}$ \\
\hline Prognosis & Good & Intermediate & Intermediate & Bad & \\
\hline
\end{tabular}

Sonographicfeatures in the molecular subtypes of breast cancer

Luminal breast cancer subtypes are of common features, LA subtype related to a favorable prognosis as they are of low grade cancers, while LB subtypes mostly are of high grade and usually associated with poor prognosis (Wu et al., 2019). Both LA and LB tumors are related to some important features in ultrasound, the noncircumscribed margins and the posterior acoustic shadowing (fig. 4). They have a hormone receptor positive status and stromal reaction, perilesional spiculations, and fibrosis resulting in the aforementioned features in ultrasound, In contrast to LA, LB subtype was found to have higher degree of vascularity, the majority of LB subtype were found to have Adler high degree (II or III) of vascularity (Rashmi et al., 2018).

HER2+ breast cancers are characterized by being of high grade, they show indistinct margins, posterior enhancement, vascularity, and calcifications (fig.5). Overexpression of the HER2 / neu gene is linked to special bad prognostic indicators, such as a high tumor grade, absence of hormone receptors, large tumor size, and axillary lymph nodal metastases.

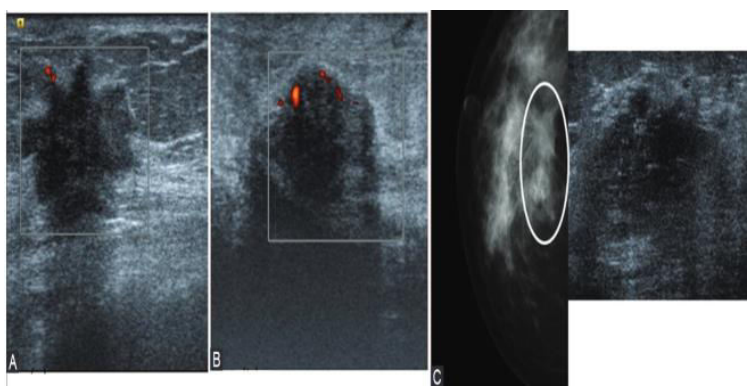

Fig. 4. (A) Luminal A subtype: Non circumscribed mass that shows a spiculated margin, posterior shadowing and minimal vascularity. (B) Luminal B (HER2-ve) subtype: Non circumscribed mass with posterior shadowing and higher vascularity. (C) Luminal B (HER2+ve) subtype: Noncircumscribed mass with microcalcifications in mammogram and posterior shadowing detected in ultrasound (Rashmi et al., 2018).

The indistinct margins and also the presence of calcifications are significantly 
related to the HER2 + status $(\mathbf{W u}$ et al., 2019).

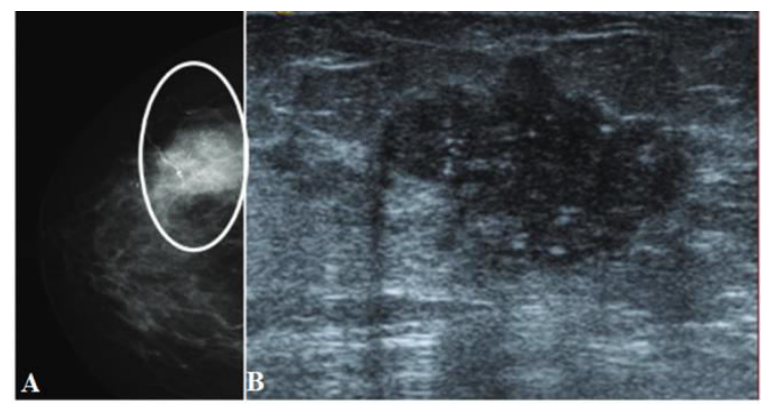

Fig.5. HER2+ subtype: Non circumscribed mass with microlobulated margins, microcalcifications (A, B) and posterior acoustic shadow (B) (Rashmi et al., 2018).

TNBC shave aggressive clinical characteristics compared to other subtypes, such as, undesirable clinical outcomes, and insufficient treatment procedures. TNBCs are more likely of high grade, they appear as circumscribed or microlobulated margins, absent echogenic border and absent calcifications, markedly hypoechoic with posterior acoustic enhancement and hypovascularization, all these features are likely due totheir negative hormone receptor status and high grade (Shin et al., 2011), the desmoplastic reaction may not appear in ultrasound despite it is actually exists due to the aforementioned rapid growth pattern with no precancerous stage. TNBCs are not commonly accompanied by DCIS which is responsible for the calcification as $82 \%$ of TNBCs are IDC with no DCIS components(Navarro et al., 2017).
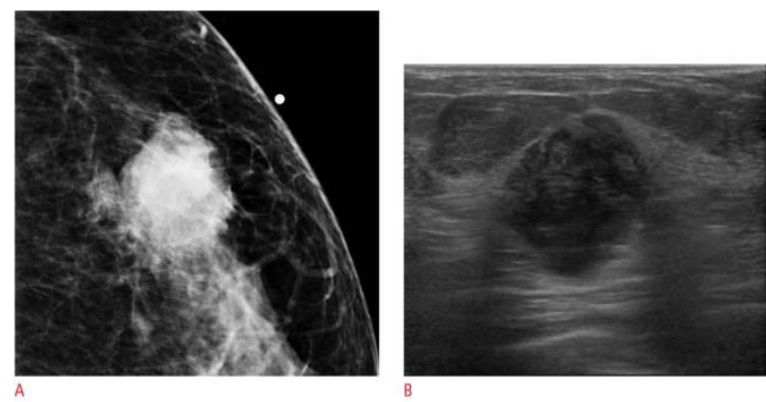

Fig.6. Imaging of TNBC with high grade
IDC. A. Mammogram reveals an irregular mass with indistinct outline and no evidence of calcifications. B. Ultrasonography reveals a circumscribed mass with irregular outline and posterior enhancement (Cho et al., 2016).

\section{MRI features in the molecular subtypes of breast cancer}

Magnetic resonance imaging features include morphology, enhancement and contrast kinetics, lesion type as regard BIRADS, was classified as enhancement of mass or non-mass. Within mass lesions, the margins of the mass and its type of enhancement are important while within non-mass lesions, the distribution and internal enhancement pattern, In both types of lesions TIC is important, it's classified into three types (persistent, plateau or washout) (Navarro et al., 2017). Most lumen $\mathrm{A}$ and lumen $\mathrm{B}$ tumors are considered an irregularly shaped mass with a spiculated or irregular margin and heterogeneous enhancement. Although there are no differences between lumen $\mathrm{A}$ and lumen B breast tumor imaging features (Dogan et al., 2018), peripheral enhancement is more common in luminal $\mathrm{B}$ than luminal $\mathrm{A}$ tumors (Kato et al., 2016).

For HER2 + manifesting as a mass, the rounded mass is the most common form with a spiculated or irregular margin, the mass-like enhancement pattern is the most common pattern in the HER2 + subtype. HER 2 + most often presents with a ductal and regional distribution. The most frequent internal enhancement for HER2 + is aggregate and heterogeneous enhancement, there is no homogeneous internal enhancement for HER2 + In addition, multifocality and multicentricity were more common in patients with HER2 + breast cancer than in other subtypes (Navarro et al., 2017). 


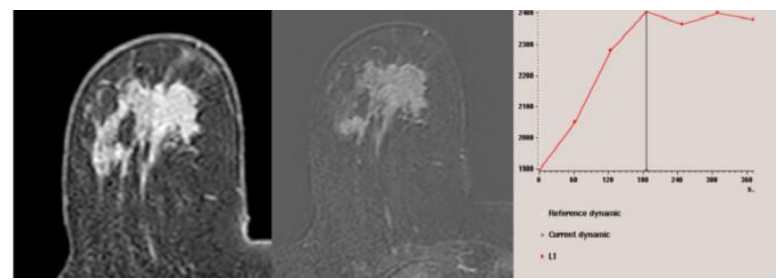

Fig.7. T1 post contrast enhancement and subtraction images shows two irregular mass lesions with spiculated and irregular margins. Both mass lesions show homogenous post contrast enhancement. TIC curve assessment: both mass lesions displayed type II curve (plateau pattern). Pathologic analysis revealed Luminal A subtype (Algazzar et al., 2020).

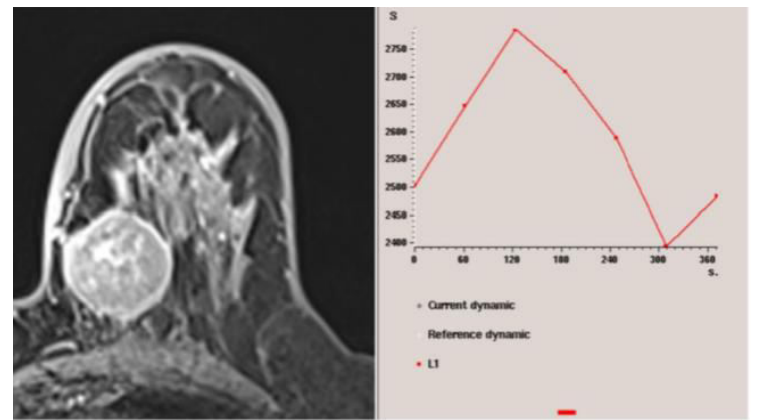

Fig.8. T1WI post contrast revealed a rounded circumscribed mass lesion with heterogenous enhancement. The lesion had malignant (washout) kinetics. Pathologic analysis revealed TNBC subtype (Algazzar et al., 2020).

Triple negative tumors presented a non-irregular shape (i.e. round, oval or lobulated) more often than other tumors, being the most common round shape, triple negative tumors presented significantly more often with a smoother margin than luminal tumors, Luminal B and HER2 +. High or very high signal intensity in T2WI, High intratumoral signal intensity in T2WI, due to necrosis which is related to a poor prognosis. TN tumors present as a marginal enhancement in most cases and as a heterogeneous enhancement in few cases,
TN not presented by homogeneous enhancement (Dogan et al., 2018).
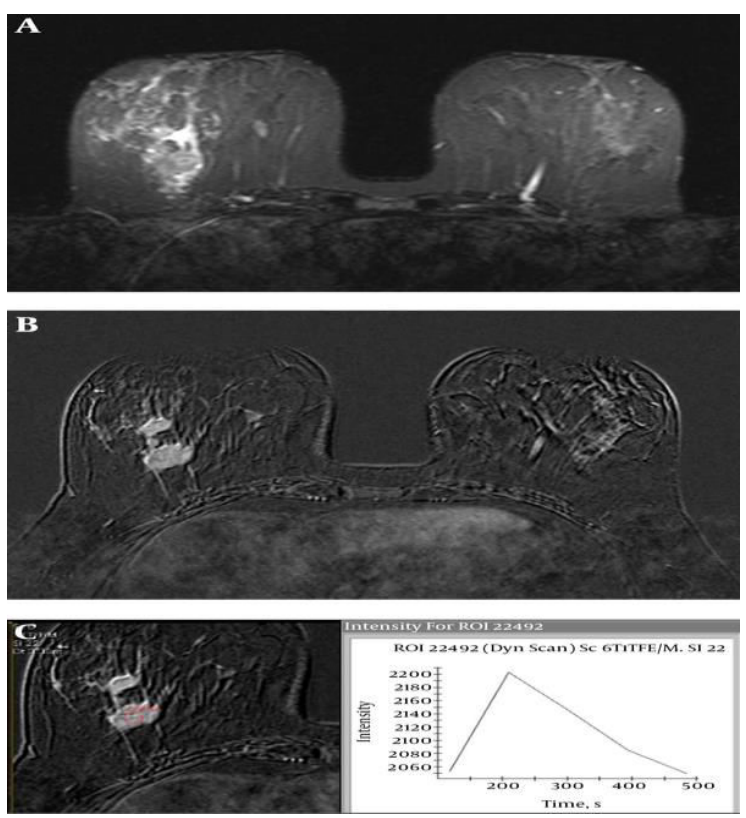

Fig.9. HER2 positive breast cancer (IDC). A. Axial STIR image shows perilesional edema around the mass lesions. B, Axial T1 post-contrast substracted image shows multifocal heterogeneously enhancing mass lesions. C, TIC indicates washout kinetic (Shin et al., 2011).

Although there are no specific pathognomonic findings of any molecular subtype in mammography, ultrasound and breast MRI, some publications have appeared which establish some common imaging features. For example, the typical presentation of type A luminal tumors on mammography is the spiculated mass. On ultrasound, irregularly shaped mass with speculated margins or even angular, posterior acoustic shadow, penetrating vessels and echogenic halo, which is the result of the stromal reaction, indicating slow growth. On MRI, a heterogeneous enhancement of the mass with irregular or spiculated margins is observed, without marked T2 hypersignal(Yong et al., 2009). 
The luminal B subtype of breast cancer does not appear to be clearly distinguished from the opposing luminal (A and HER2). Within the mammogram, we can observe an irregular, sometimes spiculated mass. Architectural distortion can be observed more frequently in this subtype. In the ultrasound, it presents as a hypervascularized, irregularly shaped, strongly hypoechoic mass, which on MRI resembles mass or non-mass enhancement (Taneja et al., 2008).

HER2-enriched tumors are seen on mammography as a mass with indistinct margins that are usually related to pleomorphic microcalcifications within the mass or within a segmental distribution, which correlate with a high grade component in situ. In the ultrasound, the lesion is markedly hypoechoic, irregularly shaped with indistinct or spiculated margins, with subsequent impaired proximity by infiltration or edema. MRI shows non-mass like enhancement in most cases (Johnson et al., 2021).
TNBC not exhibited by typical mammographic features suspected of breast cancer; which are irregular in shape, with sharp edges and suspicious calcifications. Therefore, mammography alone is insufficient for its initial diagnostic evaluation. Ultrasound has a much higher sensitivity, although its diagnostic specificity is compromised by the associated benign features seen in some of the TNBC lesions (Dogan et al., 2012). In MRI, TNBC presents itself by the typical pattern described in patients carrying the BRCA1 mutation which is: rounded mass, deeply seated, with marked hypersignal in $\mathrm{T} 2$ and enhancement in a ring. All of these imaging findings from both ultrasound and MRI are the result of central necrosis generated by the rapid growth of the tumor. In DWI, there is an increase in ADC value despite expected hypercellularity in these highly proliferating tumors. But central necrosis causes a decrease in tumor cellularity with a consequent increase in spread (Johnson et al., 2021).

Table 3. The imaging features according to the molecular classification (Cho et al., 2016).

\begin{tabular}{|c|c|c|c|}
\hline Molecular subtype & Mammography & Ultrasonography & MRI \\
\hline Luminals & $\begin{array}{l}\text { Irregular mass with } \\
\text { speculated border. }\end{array}$ & $\begin{array}{l}\text { Non-circumscribed } \\
\text { mass with posterior } \\
\text { shadowing. }\end{array}$ & $\begin{array}{l}\text {-Irregular or speculated } \\
\text { mass. } \\
\text {-presented as mass, non- } \\
\text { mass pattern may be seen } \\
\text { in luminal B. } \\
\text {-A mass with non } \\
\text { hyperintense signal on } \\
\text { T2-weighted MRI }\end{array}$ \\
\hline HER2+ & $\begin{array}{l}\text {-Microcalcifications. } \\
\text {-Malignant featuring }\end{array}$ & $\begin{array}{l}\text {-Non circumscribed } \\
\text { mass with irregular }\end{array}$ & $\begin{array}{l}\text {-A fast wash in and } \\
\text { washout kinetics } \\
\text {-Multifocal and / or }\end{array}$ \\
\hline
\end{tabular}




\begin{tabular}{|c|c|c|c|}
\hline & lesion. & $\begin{array}{l}\text { margin } \\
\text { (The circumscribed } \\
\text { margin,decreasedthe } \\
\text { possibility of HER2+ } \\
\text { type). } \\
\text { - Malignant featuring } \\
\text { lesion. }\end{array}$ & $\begin{array}{l}\text { multicentricdisease. } \\
\text {-Most commonly } \\
\text { presented as non-mass } \\
\text { enhancement either } \\
\text { ductal, regional or } \\
\text { segmental distribution. } \\
\text { - Heterogenous } \\
\text { enhancement but no } \\
\text { homogenous } \\
\text { enhancement in HER2+ }\end{array}$ \\
\hline TNBCs & $\begin{array}{l}\text { Circumscribed mass } \\
\text { without calcifications }\end{array}$ & $\begin{array}{l}\text { Circumscribed mass } \\
\text { with posterior } \\
\text { enhancement }\end{array}$ & $\begin{array}{l}\text {-A mass with internal } \\
\text { hyperintense signal on T2 } \\
\text { WI. } \\
\text {-Rim enhancement in post } \\
\text { contrast study. } \\
\text { - High ADC values due to } \\
\text { necrosis inspite high } \\
\text { cellularity. } \\
\text {-Intratumoral necrosis and } \\
\text { peritumoral edema on T2 } \\
\text { WI are associated with } \\
\text { poor response to } \\
\text { neoadjuvantchemotherapy }\end{array}$ \\
\hline
\end{tabular}

\section{Conclusion}

Breast cancer can have varying biological behavior and aggressiveness. The histopathological grade expresses the degree of malignancy of the tumor. It is important to study the relationship between carcinoma grade and imaging results, as histologic grade affects prognosis and outcome. No pathognomonic features are described in mammography, ultrasound or magnetic resonance imaging, the concept of molecular classification already has two concrete uses: predicting the Luminal A or triple negative phenotype on images and evaluating the response to neoadjuvant chemotherapy by magnetic resonance. A future application is expected in the field of radiogenomics.

\section{References}

1. Algazzar MAA, Elsayed EEM, Alhanafy AM (2020). Breast cancer imaging features as a predictor of the hormonal receptor status, HER2neu expression and molecular subtype. Egypt Journal of Radiology and Nuclear Medicine 51, 93.

2. Allarakha A, Gao $\mathbf{Y}$, Jiang $\mathbf{H}$, Wang PJ (2019). Prediction and prognosis of biologically aggressive breast cancers by the combination of DWI/DCE-MRI and immunohistochemical tumor markers. Discovery Medicine, 27 (146):7-15.

3. Boisserie LM, HurteventLG, Ferron S,Lippa N, Bonnefoi H, 
Mac GG (2013). Correlation between imaging and molecular classification of breast cancers.

4. Cho N (2016). Molecular subtypes and imaging phenotypes of breast cancer. Ultrasonography, 35(4):281288.

5. Cserni G (2020). Histological type and typing of breast carcinomas and

7. Dogan S, Ozmen S, Oz B, Imamoglu $\mathbf{H}$, Kahriman G, Zararsiz Get al.,(2018). Comparison of different dynamic contrast enhanced-magnetic resonance imaging descriptors and clinical findings among breast cancer subtypes determined based on molecular assessment. Iranian Journal of Radiology, 15 (4): e64889.

8. Fan M, Li H, Wang S, Zheng B, Zhang J, Li L (2017).Radiomic analysis reveals DCE-MRI features for prediction of molecular subtypes of breast cancer. PLOS ONE, 12 (2): $1-15$.

9. Fragomeni SM, Sciallis A, and Jeruss JS (2018). Molecular Subtypes and Local-Regional Control of Breast Cancer. Surgical Oncology Clinics of North America, 27 (1): 95-120.

10. Jenkins S, Kachur ME, Rechache K, Wells JM, Lipkowitz S (2021). Rare Breast Cancer Subtypes. Current Oncology Reports, 23: 54.

11. Johnson KS, Conant EF, Soo MS (2021). Molecular Subtypes of Breast Cancer: A Review for Breast Radiologists, Journal of Breast Imaging, 3 (1): 12-24.

12. Kato F, Kudo K, Yamashita H, Wang J, Hosoda M, Hatanaka KC et al.,(2016). Differences in the WHO classification changes over time.Pathologica, 112(1):25-41.

Diagnostic and Interventional Imaging, 94 (11): 1069-1080.

6. Dogan BE, Turnbull LW (2012).Imaging of triple-negative breast cancer. Annals of Oncology, 23 (6): 23-29.

morphological features and minimum apparent diffusion coefficient values among breast cancer subtypes using 3-tesla MRI. European Journal of Radiology, 85 (1):96-102.

13. Navarro VL, Alandete GSP, Medina GR, Blanc GE, Camarasa LN, Vilar SJ (2017). MR Imaging Findings in Molecular Subtypes of Breast Cancer According to BIRADS System. The Breast Journal, 23 (4):421-428.

14. Prat A, Pineda E, Adamo B, Galvan P, Fernandez A, Gaba L (2015). Clinical implications of the intrinsic molecular subtypes of breast cancer. Breast, 24 (2): S26S35.

15. Prat A, Ellis MJ, and Perou CM (2011). Practical implications of gene-expression-based assays for breast oncologists. Nature Reviews Clinical Oncology, 9 (1): 48-57.

16. Rashmi S, Kamala S, Murthy SS, Kotha S, Rao YS, Chaudhary KV (2018). Predicting the molecular subtype of breast cancer based on mammography and ultrasound findings. Indian Journal of Radiology and Imaging, 28(3):354361.

17. Sardanelli F, Boetes C, Borisch B, Decker T, Federico M, Gilbert 
FJet al.,(2010). Magnetic resonance imaging of the breast: recommendations from the EUSOMA working group. European Journal of Cancer, 46 (8):1296-316.

18. Shin HJ, Kim HH, Huh MO, Kim MJ, Yi A, Kim $H$ et al.,(2011). Correlation between mammographic and sonographic findings and prognostic factors in patients with node-negative invasive breast cancer. The British Journal of Radiology, 84 (997): 19-30.

19. Sinn HP and Kreipe H (2013). A Brief Overview of the WHO Classification of Breast Tumors, 4th Edition, Focusing on Issues and Updates from the 3rd Edition.Breast Care, 8:149-154.

20. Sohn Y, Han K, Seo M (2016).Immunohistochemical

Subtypes of Breast Cancer: Correlation with Clinicopathological and Radiological Factors, Iranian Journal of Radiology, 13(4):e31386.

21. Szymiczek A, Lone A, Akbari MR(2021). Molecular intrinsic versus clinical subtyping in breast cancer: A comprehensive review. Clinical Genetics,99(5):613-637.

22. Tamaki K, Sasano H, Ishida T, Ishida K, Miyashita M, Takeda
Met al.,(2010). The Correlation BetweenUltrasonographic Findings and Pathologic Features in Breast Disorders, Japanese Journal of Clinical Oncology, 40 (10): 905912.

23. Tan PH, Ellis I, Allison K, Brogi E, Fox SB, Lakhani Set al., (2020). The 2019 World Health Organization classification of tumors of the breast. Histopathology. 77(2):181-185.

24. Taneja S, Evans AJ, Rakha EA, Green AR, Ball G, Ellis IO (2008). The mammographic correlations of a new immunohistochemical classification of invasive cancer. Clinical Radiology, 63(11):12281235.

25. Wu T, Li J, Wang D, Leng X, Zhang L, Li $Z$ et al., (2019). Identification of a correlation between the sonographic appearance and molecular subtype of invasive breast cancer: A review of 311 cases. Clinical Imaging, 53:179-185.

26. Yong ITH, Evans AJ, Taneja S, Rakha EA, Green AR, Paish C (2009).Sonographic correlations with the new molecular classification of invasive cancer. European Radiology, 19 (10): 2342-2348 